\title{
Cholesterol Regulates the Endoplasmic Reticulum Exit of the Major Membrane Protein P0 Required for Peripheral Myelin Compaction
}

\author{
Gesine Saher, ${ }^{1 *}$ Susanne Quintes, ${ }^{1 *}$ Wiebke Möbius, ${ }^{1}$ Michael C. Wehr, ${ }^{1}$ Eva-Maria Krämer-Albers, ${ }^{2}$ Britta Brügger,${ }^{3}$ \\ and Klaus-Armin Nave ${ }^{1}$ \\ ${ }^{1}$ Department of Neurogenetics, Max Planck Institute of Experimental Medicine, 37075 Goettingen, Germany, ${ }^{2}$ Department of Biology, Unit of Molecular Cell \\ Biology, Mainz University, 55099 Mainz, Germany, and ${ }^{3}$ Heidelberg University Biochemistry Center, Heidelberg University, 69120 Heidelberg, Germany
}

Rapid impulse conduction requires electrical insulation of axons by myelin, a cholesterol-rich extension of the glial cell membrane with a characteristic composition of proteins and lipids. Mutations in several myelin protein genes cause endoplasmic reticulum (ER) retention and disease, presumably attributable to failure of misfolded proteins to pass the ER quality control. Because many myelin proteins partition into cholesterol-rich membrane rafts, their interaction with cholesterol could potentially be part of the ER quality control system. Here, we provide in vitro and in vivo evidence that the major peripheral myelin protein P0 requires cholesterol for exiting the ER and reaching the myelin compartment. Cholesterol dependency of P0 trafficking in heterologous cells is mediated by a cholesterol recognition/interaction amino acid consensus (CRAC) motif. Mutant mice lacking cholesterol biosynthesis in Schwann cells suffer from severe hypomyelination with numerous uncompacted myelin stretches. This demonstrates that high-level cholesterol coordinates P0 export with myelin membrane synthesis, which is required for the correct stoichiometry of myelin components and for myelin compaction.

\section{Introduction}

Cholesterol has been implicated in a variety of intracellular processes that require distinctive membrane dynamics, including the formation of membrane rafts and signal transduction. Recent studies have provided broad insight into cholesterol function at the cellular level (Dietschy and Turley, 2004; Maxfield and Tabas, 2005). However, the consequences of reduced cellular cholesterol synthesis in the context of a complex organism remain essentially unexplored.

In the vertebrate nervous system, the majority of cholesterol resides in myelin, the spiral enwrapping of axons by glial cell processes that form a compacted stack of membranes. Here, cholesterol presumably contributes to the insulator function of myelin membranes and is thus critical for rapid impulse conduction of myelinated axons (Salzer, 2003). In the peripheral nervous system (PNS), Schwann cells synthesize virtually all cholesterol that they require for myelination cell autonomously (Fu et al.,

\footnotetext{
Received Feb. 10, 2009; accepted March 22, 2009.

This work was supported by grants from the Deutsche Forschungsgemeinschaft (Sonderforschungsbereich 523), the National Multiple Sclerosis Society, the European Union FP7 (Neuron-Glia Interactions in Nerve Development and Disease), and the Hertie Stiftung (K.-A.N.). We thank Eva Niksch, Gudrun Fricke-Bode, Annette Fahrenholz, and Nicole Eiselt for excellent technical assistance. We thank Juan-Jose Archelos-Garcia and Frank Bosse for generous gifts of antibodies and Nicole Schaeren-Wiemers for providing the MAG construct. We thank Jacqueline Trotter for helpful discussion and Mika Simons for helpful comments on this manuscript.

*G.S. and S.Q. contributed equally to this work.

Correspondence should be addressed to either Dr. Gesine Saher or Dr. Klaus-Armin Nave, Department of Neurogenetics, Max Planck Institute of Experimental Medicine, Hermann-Rein-Strasse 3, 37075 Goettingen, Germany, E-mail: saher@em.mpg.de or nave@em.mpg.de.

DOI:10.1523/JNEUROSCI.0686-09.2009

Copyright $\odot 2009$ Society for Neuroscience $\quad$ 0270-6474/09/296094-11\$15.00/0
}

1998). External sources of cholesterol are dispensable, even in case of injury, when the blood-nerve barrier that shields peripheral nerves from circulation is compromised (Jurevics et al., 1998). Myelination of the PNS occurs primarily in an early postnatal period, when genes encoding myelin proteins and enzymes of the cholesterol and lipid biosynthesis pathway are concomitantly upregulated (Lemke and Axel, 1985; Nagarajan et al., 2002; Verheijen et al., 2003; D'Antonio et al., 2006). When cholesterol biosynthesis is blocked by treating animals with the squalene epoxidase inhibitor tellurium, mature Schwann cells undergo apoptosis (Berciano et al., 1998); myelin degeneration is paralleled by simultaneous transcriptional downregulation of genes involved in myelination and cholesterol biosynthesis (Toews et al., 1997). Oligodendroglial inactivation of squalene synthase (SQS), a crucial enzyme of the cholesterol biosynthesis pathway, revealed that cholesterol is rate limiting for central myelination (Saher et al., 2005). However, the mechanism of cholesterol-controlled myelin membrane growth was not identified.

In the present study, we describe a novel regulatory role of cholesterol in myelination. Elevated cholesterol is essential for efficient exiting of the major myelin protein P0 from the endoplasmic reticulum (ER) of Schwann cells. This cholesterol dependency of P0 transport can be reconstituted in non-glial cells and is mediated by a CRAC domain. Mutant mice that lack cholesterol biosynthesis in Schwann cells show perturbed P0 transport resulting in biochemical and ultrastructural abnormalities of myelin. This is paralleled by reduced myelin gene expression and severe hypomyelination. We propose that elevated cholesterol is 
essential for high-level myelin gene expression and myelin protein export enabling normal myelination by Schwann cells.

\section{Materials and Methods}

Animals. Experiments were in compliance with the animal policies of the Max Planck Institute of Experimental Medicine, approved by the German Federal State of Niedersachsen. Squalene synthase floxed mice (Saher et al., 2005) were bred with CNP-cre mice (Lappe-Siefke et al., 2003) and genotyped as described. Mutants with the genotype $\mathrm{fdft} 1{ }^{\text {flox/flox } *}$ $\mathrm{cnp} 1^{+/ \mathrm{cre}}$ were compared with littermate controls with the genotype $\mathrm{fdft}^{+/ \text {flox }} * \mathrm{cnp}^{+/ \mathrm{cre}}$. Control animals were phenotypically undistinguishable from wild-type mice.

Cell culture. Dorsal root ganglia (DRGs) were isolated from wild-type or conditional mutant embryos at embryonic day 13 (E13) and plated according to standard procedures (Kleitmann et al., 1998). Explants were cultured for 1 week [ $10 \%$ fetal calf serum and $50 \mathrm{ng} / \mathrm{ml} \mathrm{NGF}$ (Sigma) ]. To induce myelination, $50 \mu \mathrm{g} / \mathrm{ml}$ ascorbic acid was added every other day to the media [10\% lipoprotein-deficient serum (LPDS), $50 \mathrm{ng} / \mathrm{ml} \mathrm{NGF]}$ supplemented with or without $20 \mu \mathrm{g} / \mathrm{ml}$ cholesterol in ethanol. Control cultures received the same amount of ethanol as cholesterol-treated cultures. Immunocytochemistry was performed using standard procedures. Briefly, fixed cells [10 min, 4\% paraformaldehyde (PFA) in PBS] were permeabilized with ice-cold methanol at $-20^{\circ} \mathrm{C}$ for $2 \mathrm{~min}$ and incubated for $1 \mathrm{~h}$ in blocking solution [ $4 \%$ horse serum, $2 \%$ bovine serum albumin (BSA), and $0.1 \%$ porcine gelatin]. Primary antibodies were diluted in blocking solution and applied overnight at $4^{\circ} \mathrm{C}$. After washing with PBS, cells were incubated with secondary antibodies in blocking solution containing $0.2 \mu \mathrm{g} / \mathrm{ml} \mathrm{4} 4^{\prime}, 6^{\prime}$-diamidino-2-phenylindole (DAPI) for $1 \mathrm{~h}$ at room temperature. For the quantification of myelination, the total number of myelin basic protein (MBP)-positive myelin segments on each coverslip was counted, and statistics were done using the two-tailed Student's $t$ test.

SQS-deficient fibroblasts. An immortalized fibroblastoid cell line was generated from embryonic fibroblasts derived from $f d f t 1^{\text {flox/flox }}$ animals using standard procedures (Xu, 2005). Embryonic fibroblasts were immortalized by stable transfection with the SV40 large T antigen using Lipofectamine 2000 (Invitrogen). Recombination of the floxed Fdft1 locus was achieved by stable transfection with Cre recombinase and hygromycin resistance. Selection started after $24 \mathrm{~h}$ for $7 \mathrm{~d}$. Single clones were picked and expanded, giving rise to the stable cell lines verified by Southern blotting, PCR, and Western blotting. SQS null fibroblasts were maintained in DMEM with 10\% FCS.

For transfection experiments, fibroblasts were starved in 2\% LPDS (Sigma) for $24 \mathrm{~h}$ and transfected with tagged versions of myelinassociated glycoprotein (MAG) and P0 in LPDS with or without 10 $\mu \mathrm{g} / \mathrm{ml}$ cholesterol using Lipofectamine2000 (Invitrogen). After $24 \mathrm{~h}$ cells were live stained by incubation for $15 \mathrm{~min}$ on ice with primary antibodies (detecting fluorescent proteins or detecting P0) in blocking solution (2\% BSA, $0.1 \%$ porcine skin gelatin, and $2 \%$ horse serum in PBS). After washing with PBS, cells were briefly fixed in $2 \%$ PFA, washed again, and incubated with secondary antibodies (in $1 \%$ BSA/PBS) for $1 \mathrm{~h}$ at room temperature. Cells were imaged for the yellow fluorescent protein (YFP) and cyan fluorescent protein (CFP) signals of tagged transfected proteins, as well as the plasma membrane signals detected by cyanine 3 (Cy3)-coupled and Cy5-coupled secondary antibody derived fluorescence. Confocal images were obtained using a Leica DM RXA microscope with the Leica confocal software. Fluorescent probes were enhanced CFP (ECFP) (458 nm excitation, 470-520 nm detection), EYFP (514 nm excitation, 525-590 nm detection), Cy3 fluorescence (561 nm excitation, 575-625 detection), and Cy5 fluorescence (633 nm excitation, $645-750 \mathrm{~nm}$ detection). Images were than processed by using $\mathrm{NIH}$ Image software. To calculate relative plasma membrane location, the fluorescence signal of surface localized protein was converted into a mask and subtracted from the corresponding YFP or CFP images. Fluorescence intensities (FIs) of the four images were measured. Proportion of surface located $\mathrm{P} 0$ protein was calculated $\left[\mathrm{P}_{\text {surface }}=\left(1-\mathrm{FI}_{\mathrm{CFP} \text {-mask }}\right) /\right.$ $\left.\mathrm{FI}_{\mathrm{CFP}}\right]$ and normalized to surface located $\mathrm{MAG}\left[\mathrm{MAG}_{\text {surface }}=(1-\right.$ $\left.\left.\mathrm{FI}_{\text {YFP-mask }}\right) / \mathrm{FI}_{\mathrm{YFP}}\right]$. Of five independent experiments of both conditions, 68 or 76 cells were measured, respectively. Values were expressed as mean surface P0/mean surface MAG \pm SEM. Quantification of mutant P0 versus MAG was done accordingly with values expressing mean surface mutant $\mathrm{P} 0 /$ mean surface MAG \pm SEM. From three experiments, 63 cells each were measured. Student's $t$ test of uncoupled samples was applied to determine significance.

Protein analysis. For total lysates, sciatic nerves were homogenized $1 / 10 \mathrm{w} / \mathrm{v}$ on ice in lysis buffer [ $1 \%$ Triton X-100, $20 \mathrm{~mm}$ Tris-HCl, $\mathrm{pH} 8.0$, $137 \mathrm{~mm} \mathrm{NaCl}$, and $2 \mathrm{~mm}$ EDTA, with protease inhibitors (Complete; Roche)]. Purification of myelin membranes and detergent-resistant membrane (DRM) assays were performed as described previously (Saher et al., 2005). Briefly, $100 \mu \mathrm{g}$ of total lysate or $10 \mu \mathrm{g}$ of myelin were extracted with $1 \%$ Triton $\mathrm{X}-100$ for $30 \mathrm{~min}$ at $4^{\circ} \mathrm{C}$, loaded under a $0-66 \%$ Optiprep gradient (Axis-Shield), and centrifuged for $2 \mathrm{~h}$ at $200,000 \times g$. From top to bottom, six fractions were collected and analyzed by Western blotting.

Histological and immunohistochemical analyses. For standard histological analysis, mice were perfused with $4 \%$ PFA in $0.1 \mathrm{~m}$ phosphate buffer. Dissected tissue was embedded in paraffin. For immunodetection, the $\mathrm{LSAB}_{2}$ system (Dako) was used. Myelin was visualized by Gallyas silver impregnation (Gallyas, 1979). Teased fibers were prepared and immunostained as described previously (Spiegel et al., 2007). Specimens were analyzed by light microscopy (Zeiss Axiophot or using a confocal laser scanning microscope, Leica DM RXA). Images were processed by using NIH ImageJ software.

Morphology and electron microscopy. For ultrastructural analysis, animals were perfused with $2.5 \%$ glutaraldehyde and 4\% PFA in KarlssonSchulz buffer. Tissue specimens were embedded in epoxy resin (Serva) as described previously (Lappe-Siefke et al., 2003). Histological sections (1 $\mu \mathrm{m}$ ) of sciatic nerve were obtained $10 \mathrm{~mm}$ distal to the sciatic notch and stained with methylene blue. The g-ratio was defined as the numerical ratio of unmyelinated axon diameter to diameter of the same axon including the myelin sheath and was derived from at least 100 randomly chosen fibers per animal. Ultrathin sections were examined by electron microscopy (EM912AB; Zeiss). To determine the percentage of myelinated axons with noncompact areas, all myelinated axons in 10 randomly chosen EM pictures ( $n=4$ animals) were evaluated for noncompact myelin stretches. For cryoimmunoelectron microscopy, mice were perfused with $2 \%$ PFA and analyzed as described previously (Werner et al., 2007).

Mass spectrometry. Lipid extractions of sciatic nerve myelin were performed in the presence of internal lipid standards. Quantitative lipid analysis was performed by nano-electrospray ionization tandem mass spectrometry (nano-ESI-MS/MS) as described previously (Sandhoff et al., 1999). Values were expressed as mean \pm SEM. Significance was determined using Student's $t$ test of two-tailed uncoupled samples.

Antibodies. Antibodies detecting the following proteins were used: SQS (1:1000; BD Biosciences), CNP (1:300; Sigma), MAG (1:500; Millipore Bioscience Research Reagents), MBP (1:500; Dako), P0 (1:1000; generous gift from Juan-Jose Archelos-Garcia, University of Graz, Graz, Austria), Connexin32 (Cx32) (1:1000; Invitrogen), Plasmolipin (1:1000; generous gift from Frank Bosse, Heinrich Heine University, Düsseldorf, Germany), PMP22 (1:10; Acris), green fluorescent protein (1:1000; Rockland), protein disulphide isomerase (PDI) (1:1000; Stressgen), class III $\beta$ tubulin (1:1000; Covance), $\beta$-actin (1:1000; Sigma), and glyceraldehyde3 -phosphate dehydrogenase (GAPDH) (1:1000; Stressgen). Secondary antibodies were coupled to horseradish peroxidase, cyanine dyes (Jackson ImmunoResearch/Dianova), or Alexa dyes (Invitrogen).

Expression constructs. Rat P0 cDNA was obtained from the RZPD library (image clone\#7121950; German Resource Center). The MAG open reading frame (sMAG splice variant) was amplified from an expression construct (Erb et al., 2003). P0 and MAG were cloned into N1 and C1 versions of pECFP and pEYFP expression vectors (BD Biosciences Clontech) and sequences were verified. Site-directed mutagenesis was performed on pECFP(N)-P0 to introduce the mutations Y148S R151L using the Quik Change Site-Directed Mutagenesis kit (Stratagene), and mutations were confirmed by sequencing.

Gene expression analysis. RNA purification from sciatic nerve was done using the RNeasy kit (Qiagen). RNA quality and quantity was checked on the Agilent 2100 Bioanalyser (Agilent Technologies). Reverse transcription (RT) 
was done with 500 ng of RNA using the Superscript kit (Invitrogen) and random primers. Quantitative RT-PCR was performed using SybrGreen fluorescence analyzed with an ABI PRISM 7700 detection system (PerkinElmer). The relative concentrations of mRNAs were determined using the threshold cycle method. Values obtained from single animals were normalized to $\beta$-actin, Ube2I3, and 18S RNA and are expressed as mean \pm SEM. Evaluation of $\mathrm{Xbp} 1$ splice variant expression was done as described previously (Rutkowski et al., 2006): primer forward 5' $-3^{\prime}$ and reverse 5' $-3^{\prime}$; Bip, CTGAGGCGTATTTGGGAAAG CAGCATCTTTGGTTGCTTGTC; Chop, GCGACAGAGCCAGAATAACAGATGCACTTCCTTCTGGAACA; $M p z$, CCTGTCCGTGTAAACCACAATGCCCTGCTCTTCTCTTCTT; $M b p$, GCCTGTCCCTCAGCAGATTGCCTCCGTAGCCAAATCC; Pmp22, GCGGTGCTAGTGTTGCTCTTTCAGTCGTGTGTCCATTACCC; Cnp1, GACCTGGCTGGCTACTGCCCCGCTCGTGGTTGGTATCAT; Mag, TCTACCCGGGATTGTCACTGGCAGCCTCCTCTCAGATCC; Hmgcr, TGATTGGAGTTGGCACCATTGGCCAACACTGACATGC; Fdft1, ATCAGACCAGTCGCAGCTTTCGGAGAACCAGGTAGAACACA; Fasn, GTCGTCTGCCTCCAGAGCGCAACTTCCCCGACATACC; Apoe, GACCCTGGAGGCTAAGGACTAGAGCCTTCATCTTCGCAAT; Apod, ACGGAAACATCGAAGTGCTAATGGCTTCACCCTTTACTTGG; $L d l r$, GATGGCTATACCTACCCCTCAATGCTCATGCCACATCGTC; Ube2I3, AGCAGCACCAGATCCAAGATCACATTTGCGGATCTCTTCA; $18 S$ RNA AAATCAGTTATGGTTCCTTTGGTCGCTCTAGAATTACCACAGTTATCCAA; and actin, TGACAGGATGCAGAAGGAGACGCTCAGGAGGAGCAATG

\section{Results \\ Cholesterol regulates myelination ex vivo}

Previous analysis has shown that ablation of the sterol biosynthesis pathway at the level of squalene synthase specifically in oligodendrocytes resulted in a severe delay of CNS myelination (Saher et al., 2005). Moreover, oligodendrocytes express lipoprotein receptors (Zhao et al., 2007) that could also serve to enrich cholesterol to the high level that is required for myelination. To investigate whether myelination could be directly stimulated by external cholesterol, we studied DRGs, isolated from E13.5 wild-type mice, in primary culture. Myelination (by endogenous Schwann cells) was induced by adding ascorbic acid to LPDS with or without the addition of $20 \mu \mathrm{g} / \mathrm{ml}$ cholesterol. When monitoring the time course of in vitro myelination (from day 4 to 11 after ascorbic acid induction), the onset of myelination (as determined by the first appearance of MBP-positive segments) at approximately day 5 was independent of cholesterol supplementation and probably limited by basal lamina formation at this time (data not shown). However, the addition of extra cholesterol advanced myelination significantly beginning at day 6 (Fig. 1A,B). The numerical increase of myelin profiles was approximately threefold at day 6 and still twofold at day 7 . At later stages, this advance in myelination diminished, and, at day 11 , individual segments were no longer discernable and (by overall
C

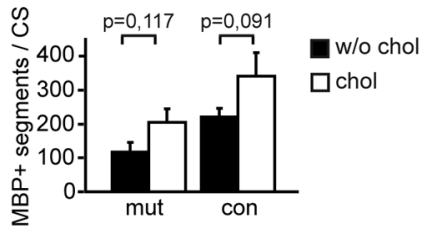

$7 d$

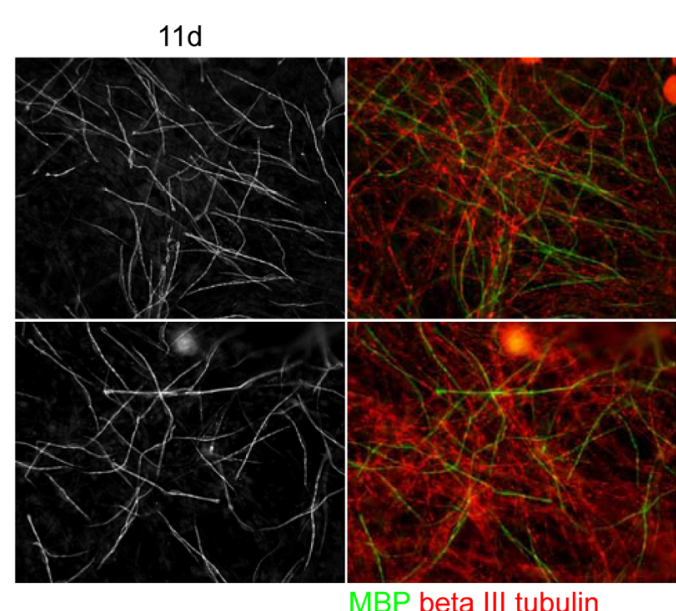

E

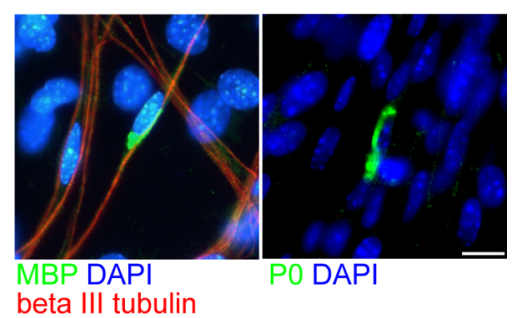

Figure 1. Cholesterol-dependent myelin formation. $A$, Quantification of the number of MBP-positive myelin segments $6-8 \mathrm{~d}$ after induction of myelination as in $\boldsymbol{B}$ showing the mean \pm SEM (3 separate experiments each with 2-3 coverslips per condition; two-tailed Student's $t$ test of uncoupled samples). B, Wild-type DRG-Schwann cell coculture 7 and $11 \mathrm{~d}$ after induction of cocultures of individual conditional mutants and controls $7 \mathrm{~d}$ after induction of myelination showing the number of MBP-positive Percentage of MBP- or P0-positive Schwann cells in which immunostaining is restricted to the cell soma. $\boldsymbol{E}$, Mutant $S$ chwann cell positive for MBP or PO (green) that fails to form a myelin segment; neurites are stained in red ( $\beta$ III tubulin). Scale bar, $10 \mu \mathrm{m}$.

fluorescence intensity) the degree of myelination was the same. These observations suggest that providing extra cholesterol accelerates myelination and that cholesterol availability is rate limiting for terminal differentiation of Schwann cells.

Next, we analyzed DRG-Schwann cell cocultures at day 7 from mice with conditional ablation of SQS specifically in Schwann cells (Saher et al., 2005) (supplemental Fig. S1, available at www.jneurosci.org as supplemental material). This allowed us to distinguish between the effect of externally supplemented cholesterol and Schwann cell-autonomous cholesterol biosynthesis. Variability was high, but mutant Schwann cells appeared to increase myelination when supplemented with cholesterol compared with cells grown in the absence of extra cholesterol (Fig. $1 C)$. Supplemented cultures reached the same extent of myelination as cultures from littermate controls grown in the absence of extra cholesterol. Despite the presence of non-recombined wildtype cells (e.g., DRG neurons and fibroblasts), cholesterol supplementation partly rescued the myelination by SQS mutant 


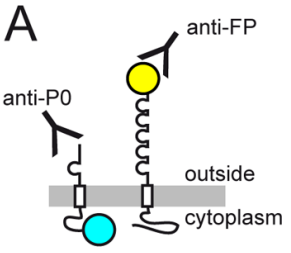

wt PO-CFP YFP-MAG

$\mathrm{B}$
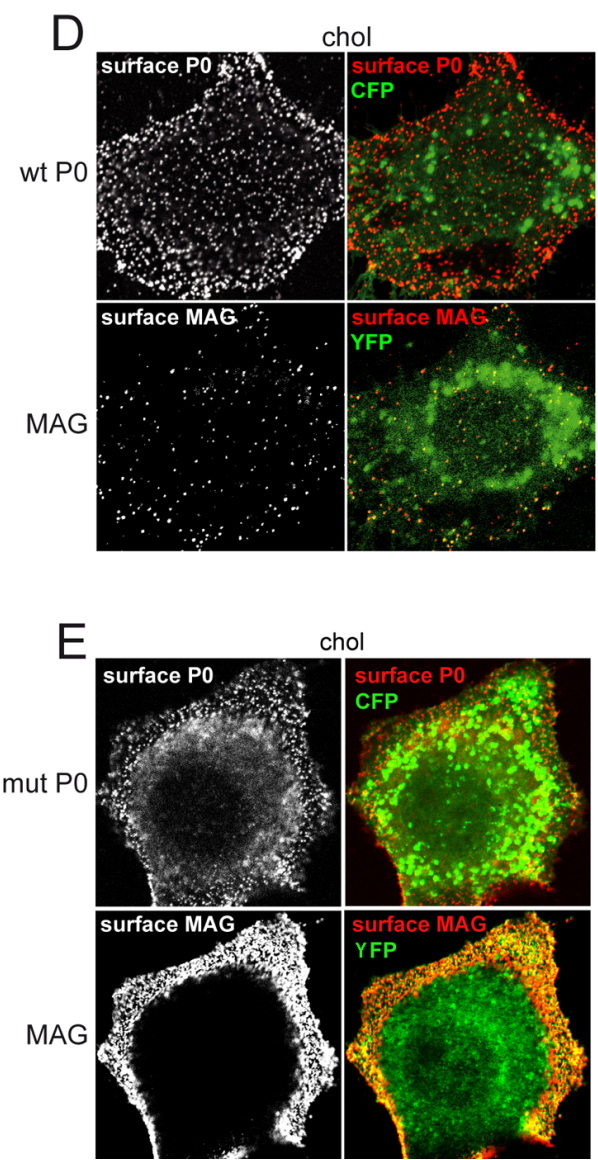

C

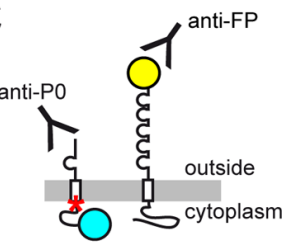

mut P0-CFP YFP-MAG
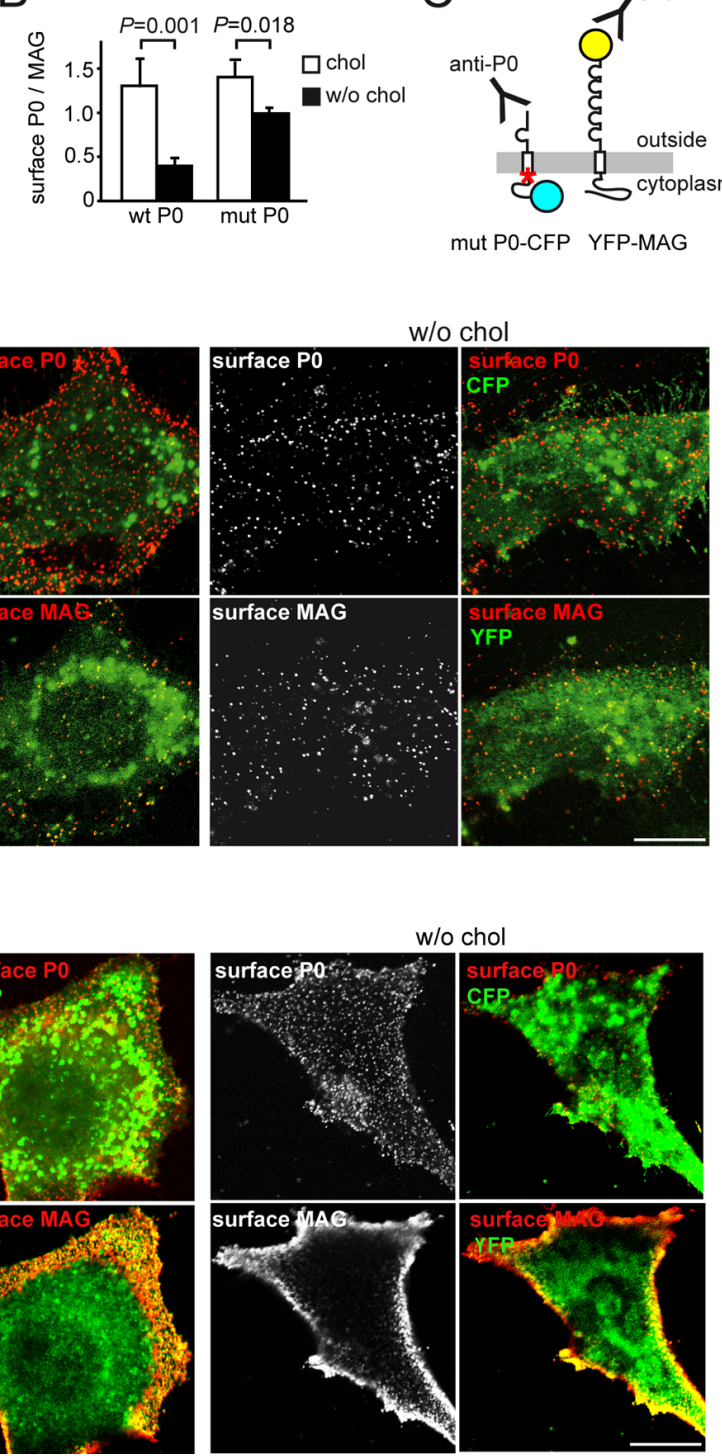

Figure 2. Reconstituting cholesterol-dependent myelin protein trafficking in heterologous cells. $A$, Structure of the transfected fusion proteins wild-type (wt) P0 - CFP and YFP-MAG. For live staining experiments determining surface localization (as shown in $D$ ), antibodies directed against the extracellular domain of PO (anti-PO) and against the fluorescent protein tag (anti-FP) were used. $\boldsymbol{B}$, Quantification of surface localization of P0-CFP and YFP-MAG in experiments as shown in $\boldsymbol{D}$ and $\boldsymbol{E}$. In the presence of cholesterol, the relative surface localization of wild-type PO (normalized to relative surface localization of MAG in the same cell) was $1.3 \pm 0.3$ but only $0.4 \pm 0.1$ without added cholesterol. In the presence of cholesterol, relative surface localization of mutant (mut) PO to MAG in the same cell was $1.4 \pm 0.1$ and $1.0 \pm 0.1$ without added cholesterol. C, Structure of transfected fusion proteins mutated P0-CFP (mutant P0-CFP, Y148S R151L) and YFP-MAG. Surface localization was determined by life stain experiments using anti-P0 antibodies and against the fluorescent protein tag (anti-FP). D, SQS null fibroblasts that were starved of cholesterol for $24 \mathrm{~h}$ in LPDS followed by transfection with both wild-type P0 - CFP and MAG-YFP and cultivation for $24 \mathrm{~h}$ in LPDS with $10 \mu \mathrm{g} / \mathrm{ml}$ cholesterol (chol) or without cholesterol (w/o chol). Surface localization of transfected proteins was visualized as described in $A$. Merged images show surface immunostain in red with the corresponding fluorescent protein in green. Scale bar, $10 \mu \mathrm{m}$. E, SQS null fibroblasts were transfected with both mutated PO - CFP and MAG-YFP as described in $\boldsymbol{D}$. local cholesterol could be involved in the differentiation of Schwann cells and the trafficking of myelin proteins.

\section{Cholesterol-dependent trafficking of myelin protein $\mathrm{PO}$}

To analyze P0 trafficking in a simplified system, we generated a cholesterol biosynthesis (SQS)-deficient fibroblastoid cell line (supplemental Fig. S2, available at www.jneurosci.org as supplemental material). SQS-deficient fibroblasts were starved of cholesterol for $24 \mathrm{~h}$ by cultivation in lipoprotein-deficient medium (LPDS) and were transiently transfected to express one of two single-span membrane proteins: the mayor myelin protein $\mathrm{P} 0$ (tagged with CFP) or the MAG (tagged with YFP) (Fig. 2A). Cells were maintained in the presence $(10 \mu \mathrm{g} / \mathrm{ml})$ or absence of cholesterol for $24 \mathrm{~h}$. In the presence of cholesterol, both proteins were detected throughout the cell, including the plasma membrane. However, P0 was primarily retained in intracellular compartments when cells were maintained in cholesterol-free medium, whereas MAG showed the same trafficking regardless of added cholesterol (supplemental Fig. S2, available at www.jneurosci.org as supplemental material). These experiments show that diminishing cholesterol content in this way does not unspecifically impair the secretory pathway but affects the analyzed membrane proteins differently.

To prove within individual cells that cholesterol-dependent trafficking is a feature specific for $\mathrm{P} 0$, we performed cotransfection experiments with $\mathrm{P} 0-\mathrm{CFP}$ and YFP-MAG. Live staining with anti-P0 and antifluorescent-protein antibodies revealed the surface localization of either protein (Fig. $2 D)$. For single cells, the P0 surface staining was quantified and normalized to MAG surface staining, the latter serving here as a cholesterol-independent internal standard. When cells were starved of cholesterol, $\mathrm{P} 0$ at the cell surface was reduced by $70 \pm 7 \%$ compared with cells grown in the presence of cholesterol (Fig. 2B). Together, these data suggest that cholesterol is required for normal trafficking of some (e.g., P0) but not all

(e.g., MAG) myelin proteins.

P0 might directly associate with cholesterol because it can be cross-linked to photo-activatable cholesterol (supplemental Fig. S6, available at www.jneurosci.org as supplemental material). P0 contains a putative cholesterol binding domain, a CRAC sequence (Epand, 2006) (residues 142-151), and we hypothesized that cholesterol-dependent trafficking of $\mathrm{P} 0$ requires this motif. Therefore, we analyzed surface localization of YFP-MAG coexpressed with mutant P0-CFP (Y148S R151L) in the same manner as described before. In the presence of cholesterol, mutant P0$\mathrm{CFP}$ was not misfolded, because it reached the surface to the same cultures of wild-type mice, the retention of myelin proteins was never observed (data not shown). These findings suggested that
Schwann cells. Nevertheless, mutant cocultures never reached the degree of myelination seen in control cocultures grown in the tation is less efficient than cell-autonomous cholesterol biosynthesis. Surprisingly, approximately a quarter of mutant Schwann cells that expressed MBP or P0 lacked a myelin sheath, confining these myelin proteins to the cell soma. Adding cholesterol reduced this feature to $\sim 10 \%$ of Schwann cells (Fig. $1 D, E$ ). In 
extent as wild-type P0-CFP (Fig. 2B). In the absence of cholesterol, the proportion of surface-resident mutant $\mathrm{P} 0$ was reduced by only $24 \pm 5 \%$ (Fig. $2 B, E$ ), i.e., onethird of that observed for wild-type P0 (70 $\pm 7 \%$; see above). Thus, the CRAC domain of P0 is clearly involved in binding cholesterol and allowing P0 transport to the cell surface. A residual cholesterol dependency is possibly attributable to other (yet undefined) domains of P0.

In an attempt to test whether the CRAC domain is also sufficient to convey cholesterol-dependent transport properties, we engineered a chimeric MAG-like membrane protein. The transmembrane domain of MAG was replaced by the transmembrane domain of wild-type $\mathrm{P} 0$, including its CRAC domain. This chimeric protein was epitope tagged and was well expressed in transfected cells. However, it was never transported to the cell surface under any condition (data not shown), presumably attributable to some misfolding of such a fusion protein.

\section{ER retention of $\mathrm{P0}$ in vivo}

To identify the subcellular compartment that controls $\mathrm{P} 0$ trafficking in vivo as a function of cholesterol availability, we performed immunoelectron microscopy of P0 in sciatic nerves of conditional SQS mutant mice. A remarkable finding in Schwann cells from mutant animals was the abnormal accumulation of immunogold particles that identified vesicular, presumably tubular profiles (Fig. 3A). These profiles had a diameter of $\sim 40 \mathrm{~nm}$ and were localized within the ER, identified by double staining for P0 and the ER marker PDI (Fig. $3 B$ ), as well as by continuity of the surrounding membrane with the nuclear envelope (data not shown). Because of the accumulation of these membranous structures, the ER of mutant Schwann cells appeared dilated and fenestrated. Concomitantly, mutant Schwann cells showed a mild ER stress response (Ron and Walter, 2007) (Fig. $3 D, E$ ). Also in control Schwann cells, the ER often appeared dilated (Fig. 3C), possibly reflecting active myelin protein synthesis. The aberrant retention of $\mathrm{P} 0$ in vesicular/tubular profiles was seen as early as postnatal day 4 (P4) in mutant mice but never in controls at all ages tested (P4, P7, P14). This finding suggests that the lack of cholesterol biosynthesis in Schwann cells limits P0 export from the ER and trafficking into the myelin compartment. In contrast, MAG and PMP22 trafficking were not visibly affected by reduced cholesterol supply, thus excluding the trivial explanation of a general block in the secretory pathway in vivo (supplemental Fig. S3, available at www.jneurosci.org as supplemental material). Moreover, these data corroborate the differential requirements of cholesterol by P0 and MAG found in vitro.

\section{Congenital hypomyelination}

Are these cell biological findings relevant for myelination in vivo? Sciatic nerves in SQS mutant animals were thin and translucent compared with those of control mice (Fig. $4 A$ ), a clear sign of hypomyelination. This hypomyelination was confirmed by
B
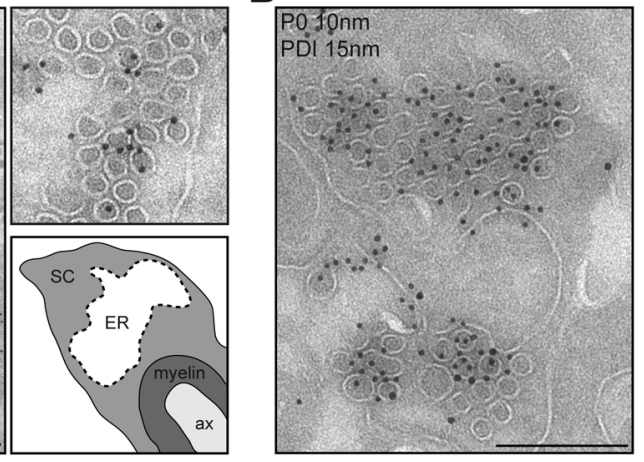

D

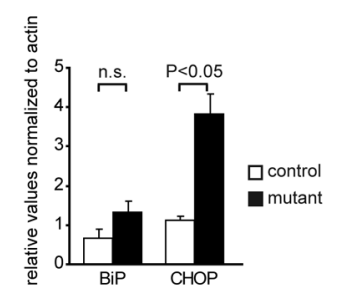

E

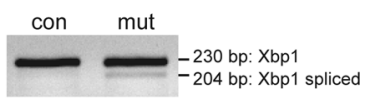

Figure 3. Cholesterol-dependent trafficking in vivo. $A$, PO detection by immunoelectron microscopy on mutant P14 sciatic nerve ( $10 \mathrm{~nm}$ gold). In addition to compact myelin, $\mathrm{PO}$ is found in vesicular/tubular profiles within the $S$ chwann cell $E R$ (arrows and (top right). The diagram clarifies structures of the picture. Scale bar, $250 \mathrm{~nm}$. B, Double detection of PO (10 real-time RT analysis of ER stress markers BiP and CHOP mRNA at P20. Data represent mean \pm SEM (Student's $t$ test, $n=3-4$ ). , The active splice variant of Xbp1 was detected in P20 mutants but not in controls by RT-PCR analysis on pooled sciatic nerve Western blotting, revealing a reduction of some but not all structural myelin proteins, as detailed below (Fig. 4 B). Moreover, also mRNAs encoding myelin proteins were severely reduced in abundance (Fig. 4C). When myelin was visualized by Gallyas silver impregnation of sciatic nerve sections, only $\sim 50 \%$ of the normally myelinated axons were likewise ensheathed in mutant mice (Fig. 4D). By electron microscopy, axons with myelin in mutant sciatic nerves were severely hypomyelinated (Fig. $4 E$ ). g-Ratio measurements demonstrated that axons of all calibers were equally affected (Fig. $4 F$ ). However, Schwann cells appeared healthy with normal nuclei that lacked signs of degeneration at the ultrastructural level (Fig. 4G). When Schwann cell nuclei (identified by morphology) were quantified (P100; $n=3$ ), sciatic nerves in control mice contained $113 \pm 7$ cells per cross section compared with $151 \pm 5$ in mutant mice. Moreover, immunostaining of activated caspase-3 (less than two positive cells per cross section in controls and mutants, $n=3$; data not shown) suggested that enhanced apoptosis was not a feature of the pathology of mutant mice. Thus, although we cannot rule out that some mutant cells were lost before the analysis, loss of Schwann cells cannot account for the hypomyelination phenotype. Furthermore, virtually all axons were ensheathed by Schwann cell processes that were occasionally very thin (Fig. $4 E$ ). Even largecaliber axons lacking myelin were engulfed by Schwann cells but arrested in this promyelin-like stage. Degenerating axons were not found, and sciatic nerves of controls and mutants contained similar absolute numbers of axons (control, $3825 \pm 336$; mutant, 
A

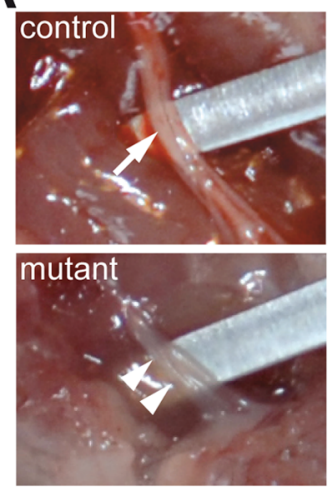

E

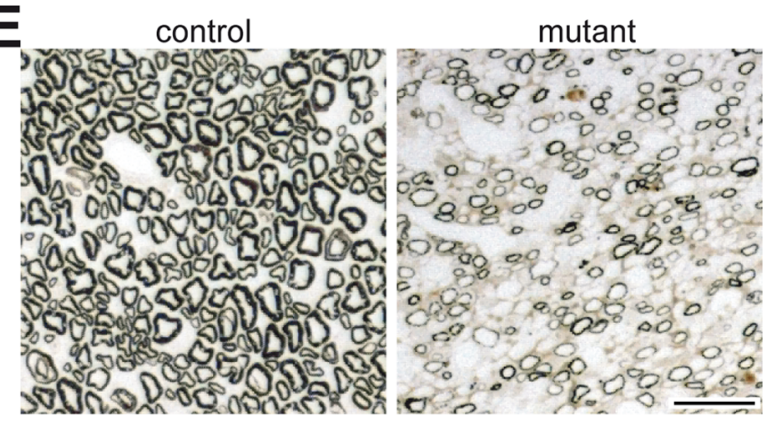

F

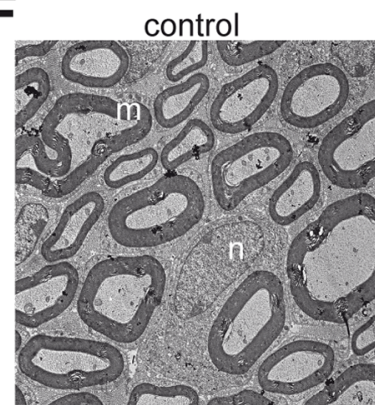

B

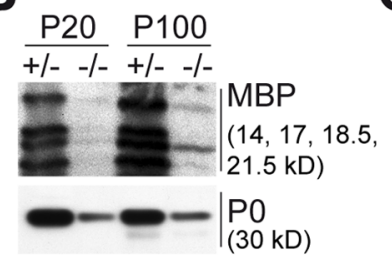

=
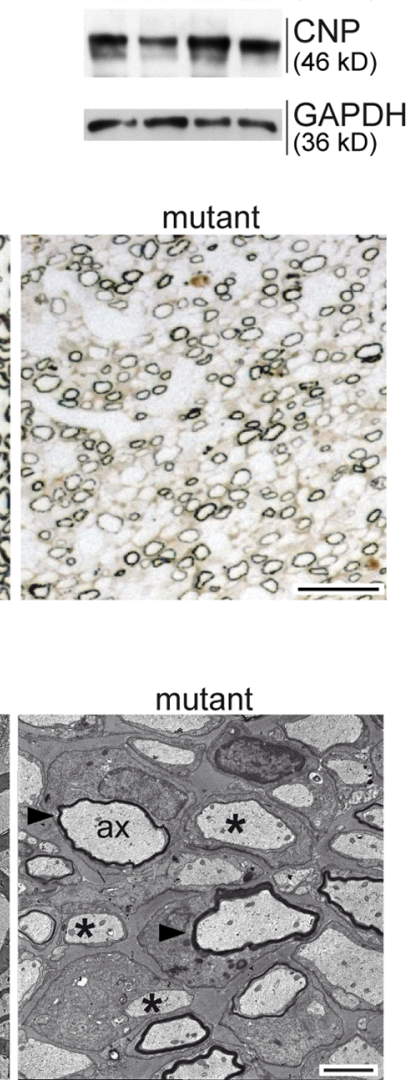

C

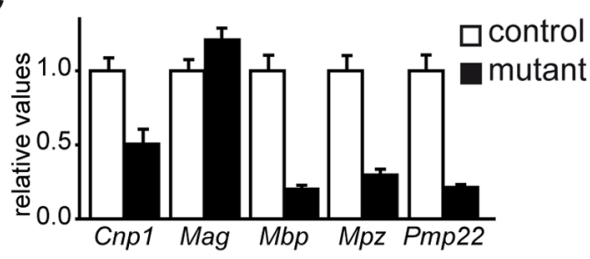

$D_{\bar{\Xi}}$

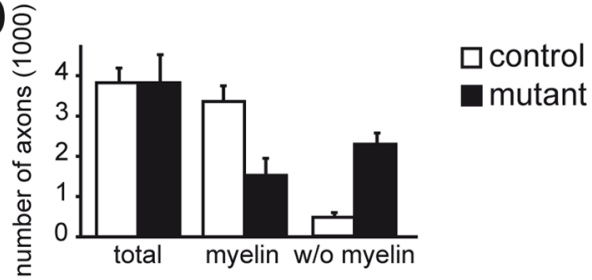

G

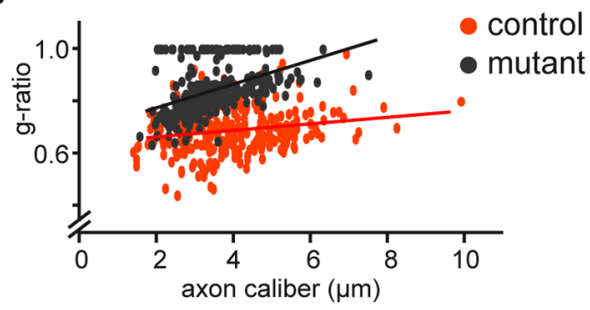

H

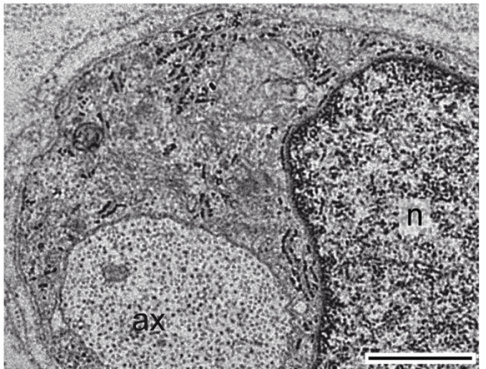

Figure 4. Congenital hypomyelination. $A$, Macroscopically (P100) control sciatic nerves (arrow) appeared opaque white because of abundant myelin, whereas mutant nerves (arrowheads) were translucent as a result of dysmyelination. $\boldsymbol{B}$, Western blot analysis of the myelin proteins MBP, PO, MAG, and CNP on total nerve extracts. Comparable staining of GAPDH shows equal loading of protein. C, Quantification of myelin gene mRNA in sciatic nerves at P2O $(n=3)$ by real-time PCR. Except for Mag, expression of all myelin genes tested was reduced in mutants. $\boldsymbol{D}$, Axon numbers are preserved in sciatic nerves of mutant mice when counted on semithin sections at P100 $(n=3)$. $\boldsymbol{E}$, Silver impregnation of myelin on sciatic nerve sections at P20. Scale bar, $20 \mu \mathrm{m}$. $\boldsymbol{F}, \boldsymbol{U l t}$ trastructure of sciatic nerves (P20) reveals normal myelination of control animals but strong hypomyelination of mutants with thinly myelinated axons (arrowheads) and axons that were devoid of myelin (asterisk). Scale bar, $2 \mu \mathrm{m}$. ax, Axon; m, myelin; $n$, Schwann cell nucleus. G, Scatter plot depicting g-ratios as a function of axonal diameter shows quantitative evidence of hypomyelination at P20 (mean g-ratios: control, $0.68 \pm 0.03 ;$ mutant, $0.84 \pm 0.02 ; p=0.002$, Student's $t$ test; $n=3$ ). $\boldsymbol{H}$, Mutant Schwann cell (P100) with normal morphology has acquired a one-to-one relationship with an axon but fails to assemble myelin. Scale bar, $1 \mu \mathrm{m}$.

$3827 \pm 692 ; \mathrm{P} 100, n=3$ ). We conclude that axonal integrity is preserved and that mutant Schwann cells are able to support axonal survival despite the absence of myelin.

\section{Altered composition of myelin}

Next, we analyzed the biochemical composition of purified myelin membranes from sciatic nerve. By nano-ESI-MS/MS mass spectrometry, cholesterol content in purified myelin membranes of mutant nerves was reduced to $60 \pm 7 \%$ of control, when normalized to phosphatidyl-choline (Fig. 5A). Interestingly, sphingomyelin, and galactosyl-ceramide were reduced to a comparable extent ( $61 \pm 8$ and $68 \pm 13 \%$, respectively), suggesting that these lipids might be coregulated and are required for the biogenesis of myelin membranes.

The overall pattern of proteins in purified myelin preparations revealed obvious differences between mutant and control mice, as visualized by silver staining (Fig. $5 B$, asterisks). Therefore, we determined the abundance of compact myelin proteins by Western blotting, including $\mathrm{P} 0, \mathrm{MBP}$, and Plasmolipin, all of which were visibly reduced. In contrast, membrane proteins that demarcate noncompacted myelin, such as MAG, CNP, and Cx32, were increased in myelin purified from mutant mice (Fig. $5 C$ ).

The reduced lipid content and altered protein composition of purified myelin could result from an impaired association of myelin proteins with lipids. To test for this, purified myelin membranes were extracted with cold Triton X-100 and separated by density gradient centrifugation. Gradient fractions were analyzed by immunoblotting (Fig. $5 D$ ). Floating DRMs were present in fractions 1 and 2, whereas soluble proteins were found in fractions 5 and 6. P0 and Plasmolipin (data not shown) were mainly 
A

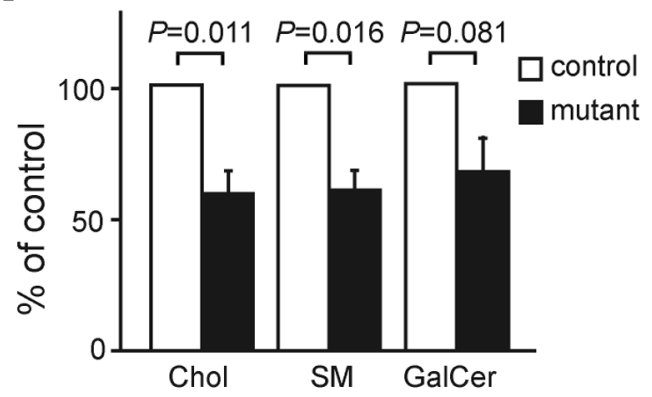

B
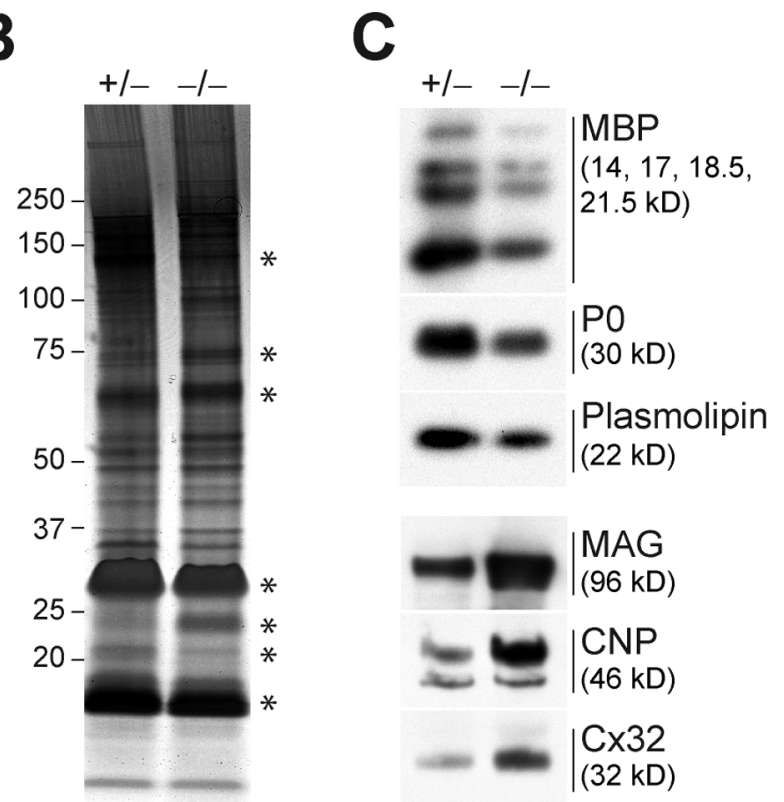

D

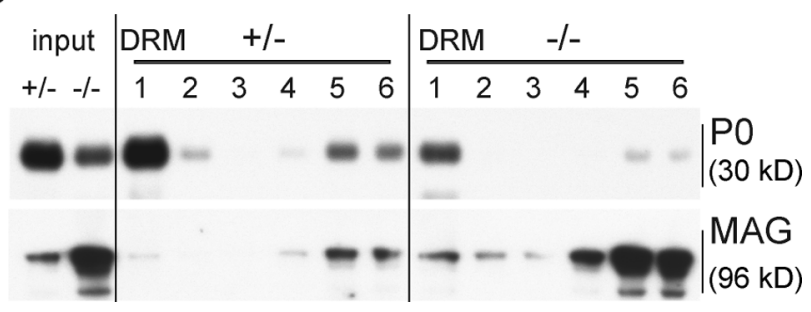

Figure 5. Altered biochemical composition of myelin. $\boldsymbol{A}$, Lipid content normalized to phosphatidyl-choline in purified myelin (P100) by nano-ESI-MS/MS. Cholesterol (Chol, $60 \pm$ $7 \%$ ), sphingomyelin (SM, $61 \pm 9 \%$ ), and galactosyl-ceramide (GalCer, $68 \pm 13 \%$ ) are reduced in mutants. $\boldsymbol{B}$, Silver staining of purified myelin proteins at P100 shows many differences (asterisks). Sizes of marker proteins are indicated on the left (kilodaltons). $C$, Western blot analysis of purified myelin (P100). Although compact myelin proteins are reduced (MBP, P0, Plasmolipin), noncompact myelin proteins (MAG, CNP, $\mathrm{Cx} 32$ ) are enriched in mutants. $\boldsymbol{D}$, In both controls and mutants, $\mathrm{PO}$ is predominately in floating DRM, whereas MAG is soluble. Purified myelin (P200) was extracted with Triton X-100 and subjected to density gradient centrifugation. Numbers indicate gradient fractions, with fractions $1-2$ representing floating proteins and fractions 5- 6 representing soluble proteins.

associated with the floating fractions 1 and 2. In contrast, MAG was predominantly found in the soluble fractions 4-6, in accordance with previous reports (Erne et al., 2002; Bosse et al., 2003). Despite the altered abundance of P0 and MAG in mutant myelin
(Fig. 5D, left lanes), the differential distribution of both proteins in DRM and soluble fractions was the same. Thus, once incorporated into myelin, these proteins retain their normal lipid association, independent of the reduced cholesterol availability in mutant Schwann cells.

\section{Increased portion of noncompact myelin}

To determine whether the altered biochemical composition of myelin influences the myelin periodicity and compaction, we studied the ultrastructure of myelinated fibers in more detail in mutant mice. Myelin, when present, revealed a normal periodicity as demonstrated by high-power electron micrographs (Fig. $6 A$ ). However, in addition to normally compacted myelin, numerous areas of noncompacted sheaths in internodal myelin were striking (Fig. $6 B$ ). These were clearly distinct from SchmidtLanterman incisures (Fig. $6 F$ ), and the presence of electrondense cytoplasm ruled out that these are ex vivo fixation artifacts. Noncompacted myelin regions varied in size from small segments to those surrounding the entire axon. When quantified in cross sections, $42 \pm 7 \%$ of the myelinated axons in mutant mice contained segments of noncompact myelin compared with $4 \pm$ $1 \%$ in controls (mean \pm SEM; $p<0.0005$ ), with both numbers including Schmidt-Lanterman incisures. We conclude that virtually all internodes in nerves of mutant mice contain extensive pockets of noncompacted myelin.

To determine the localization of abnormally expressed $\mathrm{P} 0$ and MAG, we analyzed cross sections of sciatic nerves (age P14) by immunoelectron microscopy. In both controls and mutants, MAG was localized to adaxonal membranes (Fig. 6C) and to Schmidt-Lanterman incisures (data not shown). Importantly, MAG was also detected in all abnormal noncompacted myelin segments of mutant mice (Fig. 6C), a finding reminiscent of the dysmyelinated quaking mouse (Trapp, 1988). Occasionally, entire myelin sheaths were noncompacted, displaying uniform staining of MAG (Fig. 6D). Here, numbers of wraps were small, resembling an immature stage of myelination that is normally transient in development. As expected, P0 and PMP22 immunolabeling was strong and restricted to compact myelin in both mutant and control mice (Fig. 6E) (supplemental Fig. S4, available at www.jneurosci.org as supplemental material). Thus, all myelin proteins tested are valid markers for their respective myelin compartment also in mutant mice. The lack of cholesterol synthesis in Schwann cells has, however, two consequences: overall, peripheral axons are strongly hypomyelinated (Fig. 4), and those areas of myelin that do not contain P0 are also uncompacted (Fig. 6). Indeed, we propose a model that the cholesteroldependent altered biochemical composition of myelin shifts the ratio of compacted to noncompacted myelin (Fig. 7).

\section{Discussion}

Myelination of the peripheral nervous system is under stringent axonal control and requires the synchronized expression and export of myelin-specific proteins and lipids. By genetically inactivating the cholesterol biosynthesis in Schwann cells, we gained unexpected insight into the role of cholesterol in regulating myelin formation: low levels of cholesterol are sufficient for Schwann cell survival, whereas above-threshold levels enable normal myelin formation by allowing high-level myelin gene expression and by coordinating the export of some myelin proteins (e.g., P0) but not all (e.g., MAG) from the ER into the growing myelin sheath. Consequently, the biochemical composition of myelin is changed shifting the ratio of compact to noncompact myelin. Thus, cholesterol synthesis emerges as a regulatory step of myelination. 
A

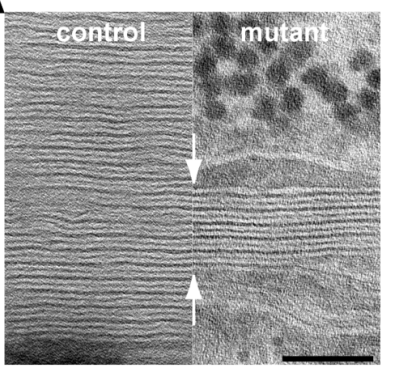

B

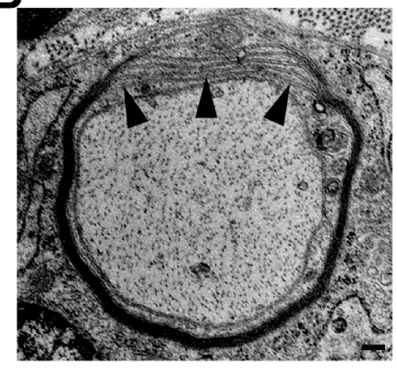

C

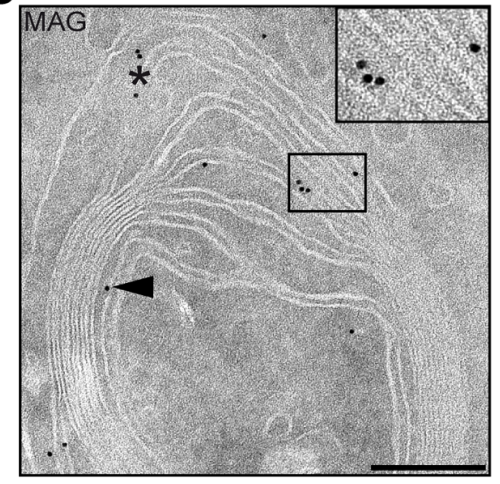

D

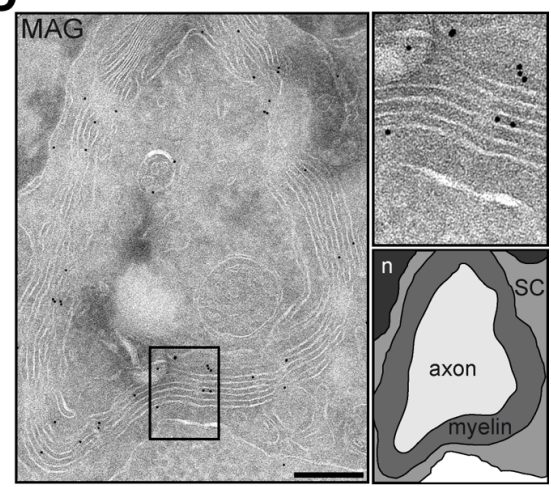

E

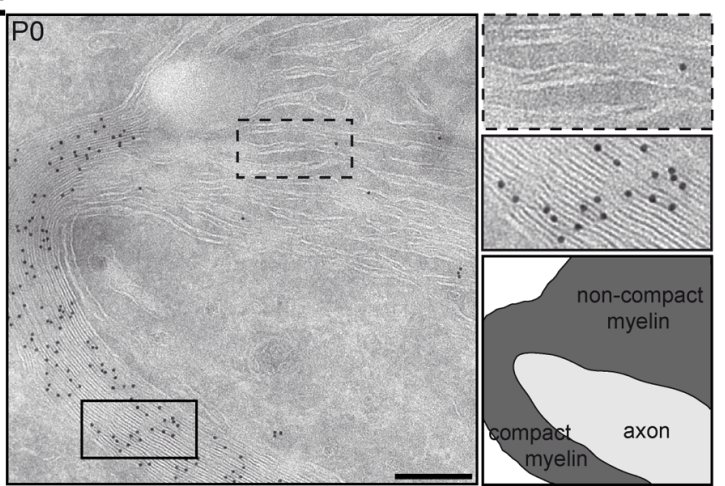

$\mathbf{F}$

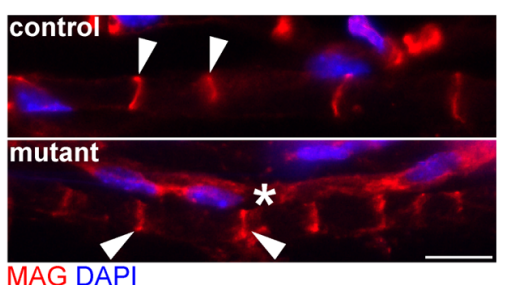

Figure 6. Defective myelin compaction. A, High-power view of compact myelin shows normal periodicity in mutant sciatic nerve (P100). Scale bar, $100 \mathrm{~nm}$. B, Ultrastructure of an axon with partially noncompacted myelin (arrowheads). $C-\boldsymbol{E}$, Immunoelectron microscopic images of sciatic nerves from $\mathrm{P} 14$ mutants detecting $\operatorname{MAG}(\boldsymbol{C}, \boldsymbol{D})$ or $\mathrm{PO}(\boldsymbol{E})$ with enlarged views of boxed areas. Diagrams clarify structures of the corresponding image (SC, Schwann cell; $n$, SC nucleus). In addition to the normal localization of MAG in the adaxonal membrane (arrowhead in C), noncompact myelin stretches also contain MAG (asterisk in C). MAG is evenly distributed in a completely uncompacted myelin sheath (D). P0 is present in compact myelin and absent from noncompact myelin areas $(\boldsymbol{E})$. Scale bars (in $\boldsymbol{B}-\boldsymbol{F}), 250 \mathrm{~nm}$. $\boldsymbol{F}$, Teased fibers preparations stained for MAG and nuclei (DAPI). In controls and mutants, MAG is found in Schmidt-Lanterman incisures (arrowheads). In addition, mutant fibers revealed a patchy staining pattern covering larger internodal regions (asterisk) probably corresponding to noncompact myelin areas. Scale bar, $10 \mu \mathrm{m}$.

Schwann cells (Fig. 7). We have identified the glial ER as a checkpoint at which the incorporation of $\mathrm{P} 0$ into the myelin sheath is regulated by direct interaction with cholesterol. We hypothesize that the fraction of $\mathrm{P} 0$ that fails to interact with cholesterol also fails the ER quality control and is, at least temporarily, retained. Interestingly, not all myelin proteins showed such cholesterol dependency: MAG expression and steady-state protein levels were not reduced in mutant sciatic nerves and MAG trafficking did not depend on cholesterol.

In $\mathrm{CHO}$ cells, the ER cholesterol level determines the conformation of the sterol regulatory element binding protein (SREBP)-cleavage activating protein (SCAP) by cholesterol binding to the sterol sensing domain of SCAP. Only at low cholesterol, SCAP binds to COPII/Sec23, thereby allowing ER exit, SREBP transport to the Golgi, and the regulation of cholesterol homeostasis (Nohturfft et al., 2000; Radhakrishnan et al., 2004; Sun et al., 2007). Interestingly, P0 contains a cholesterol binding CRAC motif at the cytoplasmic face of the transmembrane region that is conserved in vertebrates. P0 trafficking is no longer cholesterol dependent when the CRAC domain is mutated, demonstrating that this motif is functional. We also note that the basic $\mathrm{C}$ terminus of $\mathrm{P} 0$ changes its conformation in a cholesteroldependent manner (Luo et al., 2007). It remains to be determined whether the association of P0 with cholesterol renders this complex susceptible for ER export directly (e.g., by COPII/Sec23 binding) or indirectly, e.g., after differential glycosylation (Olivares et al., 2003; Fasano et al., 2008).

Our model that the cellular cholesterol level regulates the ER exit of myelin proteins is in accordance with recent observations of secretory cargo proteins in $\mathrm{CHO}$ and $\mathrm{HeLa}$ cells (Ridsdale et al., 2006; Runz et al., 2006). In these cultured cells, reduction of cholesterol by lovastatin and cyclodextrin diminished the lateral diffusion of proteins in ER membranes that was thought to interfere with the COPII machinery at ER exit sites, leading to a general reduction of protein export. In vivo studies of P0 and MAG do not allow monitoring acute effects of reduced cholesterol. However, the accumulation of P0 in abnormal vesicular/tubular profiles within the ER is compatible with altered ER membrane dynamics. Importantly, protein accumulation in the ER was not a general feature, as evidenced by normal trafficking of

\section{Cholesterol regulates ER exit of the major myelin} membrane protein

We provide experimental evidence that cholesterol is essential for the normal trafficking of P0 through the early secretory path in
MAG. This is in line with previous observations of P0 and MAG being in distinct secretory pathways (Yin et al., 2000).

Tubular profiles in the ER have been associated with the overexpression of some membrane proteins, including 3-hydroxy-3- 
methylglutaryl-coenzyme A (HMGCoA) reductase (Chin et al., 1982). However, tubular diameters are different and probably defined by protein intrinsic properties. We cannot exclude that the tubular profiles seen in the ER of mutant Schwann cells also contain HMG-CoA reductase, but this is unlikely because HMG-CoA mRNA levels were reduced to $<50 \%$ (supplemental Fig. S5, available at www.jneurosci.org as supplemental material). We suggest instead that these tubules are specific to the failure of $\mathrm{P} 0$ to exit the ER.

\section{Cholesterol controls myelin formation}

Cholesterol could regulate myelin formation by several independent ways. For example, mutant cell survival could be impaired (Kandutsch and Chen, 1977) such that the number of Schwann cells is insufficient to myelinate all axons. This is unlikely, however, because sciatic nerves in conditional mutants contained more Schwann cells than in controls. Interestingly, the mRNAs encoding apolipoprotein $\mathrm{E}$ and apolipoprotein $\mathrm{D}$ were increased in SQS mutants (1.5- to 2-fold) (supplemental Fig. S5, available at www.jneurosci.org as supplemental material). This is compatible with cholesterol being taken up by Schwann cells from non-glial sources, such as macrophages or endoneurial fibroblasts (Boyles et al., 1989; Spreyer et al., 1990). We note that the phenotype of mutant mice could not be rescued by feeding a cholesterol-rich diet (data not shown), presumably because of the blood-nerve barrier (Jurevics et al., 1998).

Second, reduced levels of the steroid hormone progesterone (a derivative of cholesterol) could limit myelination, because it is synthesized locally by Schwann cells (Koenig et al., 1995). However, progesterone levels were unchanged in sciatic nerve lysates (data not shown), suggesting that reduced progesterone synthesis cannot account for hypomyelination.

Third, the expression of myelin protein genes could depend on high intracellular cholesterol levels. Indeed, most mRNAs encoding myelin proteins (including MBP, a cytosolic myelin protein) were severely reduced in mutants. The mechanism of cholesterol-dependent feedback control of myelin genes and the potential link to the ER retention of $\mathrm{P} 0$ awaits additional investigation. To date, such concerted downregulation of myelin genes has only been observed in transcription factor mutants (Topilko et al., 1994; Jaegle et al., 1996; Le et al., 2005). Interestingly, in the many genetic null mutant mice that have been studied, no myelin structural protein was required for Schwann cells to synthesize myelin membranes. Here, cholesterol emerges as the first membrane component that is essential for myelination by Schwann cells.

The finding that high-level myelin gene expression is cholesterol dependent suggests a central role for cholesterol synthesis in the myelination program of Schwann cells. In normal development, Schwann cell differentiation is primarily controlled by axonal neuregulin-1 (NRG1) type III, an epidermal growth factorlike neuronal growth factor that activates glial ErbB receptors (Michailov et al., 2004; Taveggia et al., 2005). It has been shown recently that enhanced NRG1/ErbB signaling activates the HMG-CoA reductase gene in cultured Schwann cells (Pertusa et al., 2007) and in transgenic mice that overexpress axonal NRG1 type III (M. Schwab and C. Humml, personal communication).
Thus, glial cholesterol synthesis itself appears under axonal control. This study reveals that extra cholesterol accelerates myelination in wild-type neuron-glia cocultures implying that (in the presence of normal axonal NRG1 signaling) cholesterol is limiting for myelin membrane growth. We therefore propose a model in which axonal NRG1 induces cholesterol synthesis in Schwann cells, and the above-threshold level of cholesterol stimulates myelin gene expression and allows $\mathrm{P} 0$ export into the growing sheath enabling myelin compaction.

\section{Comparison with dysmyelinated mouse mutants}

By comparison, $M p z$ null mice are also dysmyelinated, but with significant myelin membrane synthesis (Giese et al., 1992). In P0-deficient myelin, there is a nearly complete lack of extracellular membrane compaction, whereas intracellular adhesion appears normal because of the presence of MBP (Martini et al., 1995). The aberrantly noncompacted myelin stretches in SQS mutants did not contain MBP (data not shown). This suggests that low cholesterol does not create regions of $\mathrm{P} 0$-deficient myelin but reduces compact myelin relative to the noncompacted myelin compartment (which is defined by the presence of MAG and the absence of $\mathrm{PO}$ - and $\mathrm{MBP}$-mediated myelin membrane adhesion).

Also transgenic $M p z$-overexpressing mice are dysmyelinated (Wrabetz et al., 2000). P0 accumulates in post-ER compartments, such as Golgi and endosomes but not within the ER (Yin et al., 2000). This type of P0 mislocalization differs dramatically from that in our SQS mutants. Thus, P0 overexpression cannot explain the phenotype of conditional SQS mice. In fact, the attenuated myelin gene expression, in combination with a limited ER stress response, may save mutant Schwann cells from such overexpression defects.

\section{Relevance for human myelin disease}

Abnormal expression of myelin proteins in the PNS has been associated with Schwann cell dysfunction in specific forms of inherited neuropathies (Shy et al., 2002). The phenotype of SQS conditional mutants is most similar to a congenital hypomyelinating neuropathy $(\mathrm{CHN})$. This disorder is characterized by an early onset, severe hypomyelination and dramatic neurological impairments (Shy et al., 2002; Suter and Scherer, 2003). Although no CHN subform has been linked to genes of cholesterol metabolism yet, we note that neuropathy can be part of a complex syndrome in patients with cholesterol-related disorders, i.e., 
Smith-Lemli-Opitz syndrome (Acosta, 1994) and NiemannPick type C disease (Zafeiriou et al., 2003).

Neurological impairments of neuropathies are generally caused by the secondary axonal degeneration (Suter and Scherer, 2003). It was surprising that the axonal integrity was well preserved in conditional SQS mutants. Although Schwann cells failed to myelinate, conditional mutants showed no signs of axonal degeneration, neurofilament abnormalities, or axonal transport defects, even in older animals. Interestingly, all axons were engulfed by mutant Schwann cells that appeared fully competent to support long-term axonal integrity. Although this function is molecularly not defined, its execution is obviously independent of myelin formation. In conditional SQS mutant mice, the two functions of Schwann cells, myelination and long-term axonal support, have been genetically uncoupled.

\section{References}

Acosta PB (1994) RSH/SLO (Smith-Lemli-Opitz) syndrome: designing a high cholesterol diet for the SLO syndrome. Am J Med Genet 50:358-363.

Berciano MT, Calle E, Fernández R, Lafarga M (1998) Regulation of Schwann cell numbers in tellurium-induced neuropathy: apoptosis, supernumerary cells and internodal shortening. Acta Neuropathol 95:269-279.

Bosse F, Hasse B, Pippirs U, Greiner-Petter R, Müller HW (2003) Proteolipid plasmolipin: localization in polarized cells, regulated expression and lipid raft association in CNS and PNS myelin. J Neurochem 86:508-518.

Boyles JK, Zoellner CD, Anderson LJ, Kosik LM, Pitas RE, Weisgraber KH, Hui DY, Mahley RW, Gebicke-Haerter PJ, Ignatius MJ (1989) A role for apolipoprotein E, apolipoprotein A-I, and low density lipoprotein receptors in cholesterol transport during regeneration and remyelination of the rat sciatic nerve. J Clin Invest 83:1015-1031.

Chin DJ, Luskey KL, Anderson RG, Faust JR, Goldstein JL, Brown MS (1982) Appearance of crystalloid endoplasmic reticulum in compactin-resistant Chinese hamster cells with a 500-fold increase in 3-hydroxy-3methylglutaryl-coenzyme A reductase. Proc Natl Acad Sci USA 79:1185-1189.

D’Antonio M, Michalovich D, Paterson M, Droggiti A, Woodhoo A, Mirsky R, Jessen KR (2006) Gene profiling and bioinformatic analysis of Schwann cell embryonic development and myelination. Glia 53:501-515.

Dietschy JM, Turley SD (2004) Thematic review series: brain lipids. Cholesterol metabolism in the central nervous system during early development and in the mature animal. J Lipid Res 45:1375-1397.

Epand RM (2006) Cholesterol and the interaction of proteins with membrane domains. Prog Lipid Res 45:279-294.

Erb M, Steck AJ, Nave KA, Schaeren-Wiemers N (2003) Differential expression of L- and S-MAG upon cAMP stimulated differentiation in oligodendroglial cells. J Neurosci Res 71:326-337.

Erne B, Sansano S, Frank M, Schaeren-Wiemers N (2002) Rafts in adult peripheral nerve myelin contain major structural myelin proteins and myelin and lymphocyte protein (MAL) and CD59 as specific markers. J Neurochem 82:550-562.

Fasano A, Amoresano A, Rossano R, Carlone G, Carpentieri A, Liuzzi GM, Pucci P, Riccio P (2008) The different forms of PNS myelin P0 protein within and outside lipid rafts. J Neurochem 107:291-301.

Fu Q, Goodrum JF, Hayes C, Hostettler JD, Toews AD, Morell P (1998) Control of cholesterol biosynthesis in Schwann cells. J Neurochem 71:549-555.

Gallyas F (1979) Silver staining of myelin by means of physical development. Neurol Res 1:203-209.

Giese KP, Martini R, Lemke G, Soriano P, Schachner M (1992) Mouse P0 gene disruption leads to hypomyelination, abnormal expression of recognition molecules, and degeneration of myelin and axons. Cell 71:565-576.

Jaegle M, Mandemakers W, Broos L, Zwart R, Karis A, Visser P, Grosveld F, Meijer D (1996) The POU factor Oct-6 and Schwann cell differentiation. Science 273:507-510.

Jurevics H, Bouldin TW, Toews AD, Morell P (1998) Regenerating sciatic nerve does not utilize circulating cholesterol. Neurochem Res 23:401-406.

Kandutsch AA, Chen HW (1977) Consequences of blocked sterol synthesis in cultured cells. DNA synthesis and membrane composition. J Biol Chem 252:409-415.

Kleitmann N, Wood PM, Bunge RP (1998) Tissue culture methods for the study of myelination. In: Cultering nerve cells (Banker G, Goslin K, eds), pp 545-594. Cambridge, MA: MIT.

Koenig HL, Schumacher M, Ferzaz B, Thi AN, Ressouches A, Guennoun R, Jung-Testas I, Robel P, Akwa Y, Baulieu EE (1995) Progesterone synthesis and myelin formation by Schwann cells. Science 268:1500-1503.

Lappe-Siefke C, Goebbels S, Gravel M, Nicksch E, Lee J, Braun PE, Griffiths IR, Nave KA (2003) Disruption of Cnp1 uncouples oligodendroglial functions in axonal support and myelination. Nat Genet 33:366-374.

Le N, Nagarajan R, Wang JY, Svaren J, LaPash C, Araki T, Schmidt RE, Milbrandt J (2005) Nab proteins are essential for peripheral nervous system myelination. Nat Neurosci 8:932-940.

Lemke G, Axel R (1985) Isolation and sequence of a cDNA encoding the major structural protein of peripheral myelin. Cell 40:501-508.

Luo X, Sharma D, Inouye H, Lee D, Avila RL, Salmona M, Kirschner DA (2007) Cytoplasmic domain of human myelin protein zero likely folded as \{beta\}-structure in compact myelin. Biophys J 92:1585-1597.

Martini R, Mohajeri MH, Kasper S, Giese KP, Schachner M (1995) Mice doubly deficient in the genes for P0 and myelin basic protein show that both proteins contribute to the formation of the major dense line in peripheral nerve myelin. J Neurosci 15:4488-4495.

Maxfield FR, Tabas I (2005) Role of cholesterol and lipid organization in disease. Nature 438:612-621.

Michailov GV, Sereda MW, Brinkmann BG, Fischer TM, Haug B, Birchmeier C, Role L, Lai C, Schwab MH, Nave KA (2004) Axonal neuregulin-1 regulates myelin sheath thickness. Science 304:700-703.

Nagarajan R, Le N, Mahoney H, Araki T, Milbrandt J (2002) Deciphering peripheral nerve myelination by using Schwann cell expression profiling. Proc Natl Acad Sci U S A 99:8998-9003.

Nohturfft A, Yabe D, Goldstein JL, Brown MS, Espenshade PJ (2000) Regulated step in cholesterol feedback localized to budding of SCAP from ER membranes. Cell 102:315-323.

Olivares C, Solano F, García-Borrón JC (2003) Conformation-dependent post-translational glycosylation of tyrosinase. Requirement of a specific interaction involving the $\mathrm{CuB}$ metal binding site. J Biol Chem 278:15735-15743.

Pertusa M, Morenilla-Palao C, Carteron C, Viana F, Cabedo H (2007) Transcriptional control of cholesterol biosynthesis in Schwann cells by axonal neuregulin 1. J Biol Chem 282:28768-28778.

Radhakrishnan A, Sun LP, Kwon HJ, Brown MS, Goldstein JL (2004) Direct binding of cholesterol to the purified membrane region of SCAP: mechanism for a sterol-sensing domain. Mol Cell 15:259-268.

Ridsdale A, Denis M, Gougeon PY, Ngsee JK, Presley JF, Zha X (2006) Cholesterol is required for efficient endoplasmic reticulum-to-Golgi transport of secretory membrane proteins. Mol Biol Cell 17:1593-1605.

Ron D, Walter P (2007) Signal integration in the endoplasmic reticulum unfolded protein response. Nat Rev Mol Cell Biol 8:519-529.

Runz H, Miura K, Weiss M, Pepperkok R (2006) Sterols regulate ER-export dynamics of secretory cargo protein ts-O45-G. EMBO J 25:2953-2965.

Rutkowski DT, Arnold SM, Miller CN, Wu J, Li J, Gunnison KM, Mori K, Sadighi Akha AA, Raden D, Kaufman RJ (2006) Adaptation to ER stress is mediated by differential stabilities of pro-survival and pro-apoptotic mRNAs and proteins. PLoS Biol 4:e374.

Saher G, Brügger B, Lappe-Siefke C, Möbius W, Tozawa R, Wehr MC, Wieland F, Ishibashi S, Nave KA (2005) High cholesterol level is essential for myelin membrane growth. Nat Neurosci 8:468-475.

Salzer JL (2003) Polarized domains of myelinated axons. Neuron 40:297-318.

Sandhoff R, Brügger B, Jeckel D, Lehmann WD, Wieland FT (1999) Determination of cholesterol at the low picomole level by nano-electrospray ionization tandem mass spectrometry. J Lipid Res 40:126-132.

Shy ME, Garbern JY, Kamholz J (2002) Hereditary motor and sensory neuropathies: a biological perspective. Lancet Neurol 1:110-118.

Spiegel I, Adamsky K, Eshed Y, Milo R, Sabanay H, Sarig-Nadir O, Horresh I, Scherer SS, Rasband MN, Peles E (2007) A central role for Necl4 (SynCAM4) in Schwann cell-axon interaction and myelination. Nat Neurosci 10:861-869.

Spreyer P, Schaal H, Kuhn G, Rothe T, Unterbeck A, Olek K, Müller HW (1990) Regeneration-associated high level expression of apolipoprotein 
D mRNA in endoneurial fibroblasts of peripheral nerve. EMBO J 9:2479-2484

Sun LP, Seemann J, Goldstein JL, Brown MS (2007) Sterol-regulated transport of SREBPs from endoplasmic reticulum to Golgi: Insig renders sorting signal in Scap inaccessible to COPII proteins. Proc Natl Acad Sci U S A 104:6519-6526.

Suter U, Scherer SS (2003) Disease mechanisms in inherited neuropathies. Nat Rev Neurosci 4:714-726.

Taveggia C, Zanazzi G, Petrylak A, Yano H, Rosenbluth J, Einheber S, Xu X, Esper RM, Loeb JA, Shrager P, Chao MV, Falls DL, Role L, Salzer JL (2005) Neuregulin-1 type III determines the ensheathment fate of axons. Neuron 47:681-694.

Toews AD, Roe EB, Goodrum JF, Bouldin TW, Weaver J, Goines ND, Morell P (1997) Tellurium causes dose-dependent coordinate down-regulation of myelin gene expression. Brain Res Mol Brain Res 49:113-119.

Topilko P, Schneider-Maunoury S, Levi G, Baron-Van Evercooren A, Chennoufi AB, Seitanidou T, Babinet C, Charnay P (1994) Krox-20 controls myelination in the peripheral nervous system. Nature 371:796-799.

Trapp BD (1988) Distribution of the myelin-associated glycoprotein and P0 protein during myelin compaction in quaking mouse peripheral nerve. J Cell Biol 107:675-685.
Verheijen MH, Chrast R, Burrola P, Lemke G (2003) Local regulation of fat metabolism in peripheral nerves. Genes Dev 17:2450-2464.

Werner HB, Kuhlmann K, Shen S, Uecker M, Schardt A, Dimova K, Orfaniotou F, Dhaunchak A, Brinkmann BG, Möbius W, Guarente L, Casaccia-Bonnefil P, Jahn O, Nave KA (2007) Proteolipid protein is required for transport of sirtuin 2 into CNS myelin. J Neurosci 27:7717-7730.

Wrabetz L, Feltri ML, Quattrini A, Imperiale D, Previtali S, D’Antonio M, Martini R, Yin X, Trapp BD, Zhou L, Chiu SY, Messing A (2000) P(0) glycoprotein overexpression causes congenital hypomyelination of peripheral nerves. J Cell Biol 148:1021-1034.

Xu J (2005) Preparation, culture, and immortalization of mouse embryonic fibroblasts. Curr Protoc Mol Biol Chapter 28:Unit 28.1.

Yin X, Kidd GJ, Wrabetz L, Feltri ML, Messing A, Trapp BD (2000) Schwann cell myelination requires timely and precise targeting of $\mathrm{P}(0)$ protein. J Cell Biol 148:1009-1020.

Zafeiriou DI, Triantafyllou P, Gombakis NP, Vargiami E, Tsantali C, Michelakaki E (2003) Niemann-Pick type C disease associated with peripheral neuropathy. Pediatr Neurol 29:242-244.

Zhao S, Hu X, Park J, Zhu Y, Zhu Q, Li H, Luo C, Han R, Cooper N, Qiu M (2007) Selective expression of LDLR and VLDLR in myelinating oligodendrocytes. Dev Dyn 236:2708-2712. 